\title{
Garlic (Allium sativum Linn) Mitigates Experimentally induced Hepatotoxicity and Nephrotoxicity in Commercial Chickens
}

OMOLADE ABODUNRIN OLADELE ( $\sim$ lade.oladele@gmail.com )

University of Ibadan Faculty of Veterinary Medicine https://orcid.org/0000-0002-6745-1119

Helen Oyebukola Nottidge

University of Ibadan Faculty of Veterinary Medicine

Oluwaseun Olanrewaju Esan

University of Ibadan Faculty of Veterinary Medicine

Adetolase Azizat Bakre

University of Ibadan Faculty of Veterinary Medicine

\section{Research Article}

Keywords: Acetaminophen, chicken, garlic, hepatotoxicity, nephrotoxicity

Posted Date: February 26th, 2021

DOI: https://doi.org/10.21203/rs.3.rs-246140/v1

License: (c) (i) This work is licensed under a Creative Commons Attribution 4.0 International License.

Read Full License 


\section{Abstract}

Intoxication as well as infectious and metabolic diseases resulting in liver and kidney damage are major causes of losses in poultry species. While there are no specific drugs for reversal of pathophysiology of the liver and kidney, certain herbs such as garlic have been shown to improve livability of livestock and poultry. Its probable potential at enhancing the functionality of these organs in the face of injuries/insults by intoxication was investigated.

Chicken subgroup supplemented with $0.25 \%$ garlic-meal and administered $300 \mathrm{mg} / \mathrm{kg}$ acetaminophen at 8week-old ( $G 1 ; n=25)$ and subgroup without acetaminophen ( $G 2 ; n=25)$, those not supplemented and without acetaminophen (NG2; $\mathrm{n}=25)$ and those not initially supplemented but administered acetaminophen and later supplemented (NG1 g; $\mathrm{n}=20)$ had higher Newcastle disease vaccinal antibody titers $(8.0 \pm 0.25,7.5 \pm 0.24,7.6 \pm 0.23,8.14 \pm 0.31$, respectively) in comparison with subgroup without supplementation and administered acetaminophen ( $N G l ; n=25-7.13 \pm 0.38$ ). Serum protein levels had a similar pattern. AST levels $(U / L)$ were significantly higher $(p<0.05)$ in acetaminophen subgroups $G 1$ (79.4 \pm 5.79$)$ and NG1 (83.7 \pm 7.5$)$ than their respective controls G2 (75.1 \pm 7.85$)$ and NG2 (65.2 \pm 6.84$)$ with no corresponding increase in CK levels. At 2-, 7- and 14-days post-administration of acetaminophen (paa), creatinine $(\mathrm{mg} / \mathrm{dl})$ was significantly higher in $\mathrm{G} 1(1.44 \pm 0.01,1.42 \pm 0.01,1.44 \pm 0.02)$ and NG1 $(1.47 \pm 0.01$, $1.51 \pm 0.01,1.47 \pm 0.01)$ than in $\mathrm{G} 2(1.16 \pm 0.05,1.23 \pm 0.01,1.26 \pm 0.06)$ and NG2 $(1.31 \pm 0.06,1.29 \pm 0.02$, $1.31 \pm 0.05)$. A similar pattern was observed at 21 days paa.

Clinical signs and pathological lesions associated with toxic dose of acetaminophen in liver and kidneys were reversed (NG1g). Thus, exhibiting the potential of garlic in protection against hepatorenal damage or injury.

\section{Introduction}

Liver and kidneys are critical organs to the physiology and metabolism of the animal body. The liver has been described as a sophisticated chemical laboratory where numerous chemical transformations in the body take place. It produces some chemicals, modifies others to allow the body to use them and neutralizes an array of toxins. The avian liver is necessary for metabolism of carbohydrate and metabolites, drugs and chemicals, protein synthesis and has antimicrobial activities via the Kupffer cells, while the kidney is responsible for excretion of metabolites and osmoregulation (Doneley, 2011). However, certain conditions of poultry affect the normal functioning of these organs with deleterious effects on the health and productivity of affected birds. Mycotoxicoses are common and major conditions of poultry with clinical and subclinical manifestations of intoxications via liver and kidney damage. Mycotoxins such as aflatoxin and ochratoxin, are common contaminants of poultry feed and feed ingredients, occurring mostly in multiples (Davegowda and Murthy, 2005). Fatty liver syndrome is also a metabolic condition with grave effect on liver function. Certain infectious diseases also affect the functioning of the liver and kidneys of poultry species; these include fowl typhoid, pullorum disease, histomoniasis, avian leucosis, Marek's disease, and others. 
While there are no specific drugs for the reversal of pathophysiology of the liver and kidneys, certain herbs have been shown to improve the liveability of livestock and poultry. The use of herbs in the treatment of diseases and general improvement of well-being is known as herbal medicine. According to Abdel-Aziz et al. (2016), herbal medicine refers to using plant seed, berries, roots, leaves, bark or flower for medicinal purposes. Some commonly used herbs include ginger, aloe vera, moringa, garlic and more.

Plant extracts and spices can play a role in supporting both performance and health status of animals (Gill, 2000; Manzanilla et al., 2001). Beneficial effects of herbal extracts or active substances in animal nutrition may include the stimulation of appetite and feed intake, the improvement of endogenous digestive enzyme secretion, activation of immune response and antibacterial, antiviral, antioxidant and anthelminthic actions. Herbs are used as feed additives due to their suitability and preference, lower cost of production, reduced risk of toxicity, minimal health hazards and environmental friendliness (Davegowda, 1996). Recent research works on herbal formulations as feed additives have shown encouraging results as regards weight gain, feed efficiency, lowered mortality and increased livability in poultry birds (Deepak et al., 2002; Jahan et al., 2008; Oladele and Bakare, 2011; Oladele et al., 2012). Herbs or spices like ginger (Zingiber officinale) and garlic (Allium sativum) have been reported to possess useful pharmacologically potent chemical substances for use in poultry production (Onu, 2010).

Garlic (Allium sativum) is both an herbal medicine and a spice belonging to the onion family Alliceae. It is used for the prevention and treatment of a variety of diseases (Adibmoradi et al., 2006). Garlic has several beneficial effects for humans and animals, exhibiting antimicrobial, anti-oxidant and antihypertensive properties (Konjufca et al., 1997). Studies in animals have suggested that allicin, the main biological active component in garlic, has the potential to exhibit anti-tumor activity in mice (Sivam, 2001). Also, Ghazanfari et al. (2002) observed significant increase in delayed type hyper-sensitivity response, but not in antibody response to sheep red blood cells in mice. Ancient Egyptians consider garlic as an irreplaceable nutritional supplement; they fed their slaves with it to make them strong and capable of doing more work (Topak et al., 2005).

Liver and kidney damage in poultry species due to intoxication as well as infectious and metabolic diseases which are common occurrences, is a major cause of losses in the industry. In view of the benefits of garlic preparations in humans and animals alike, it is probable potential at enhancing the functionality of the liver and kidneys in poultry species, in the face of constant injuries or insults by any of the afore mentioned factors is yet to be investigated. This study was therefore carried out to investigate the probable protective effects of garlic against liver and kidney damage or injuries in chickens.

\section{Materials And Methods}

Rearing of experimental chickens: One-day-old cockerels (120) were purchased from a commercial hatchery in Ibadan, Nigeria out of which 15 were bled for the determination of Newcastle disease antibody titer. Rearing was carried out in open-sided tropical cages at the Department of Veterinary 
Medicine, University of Ibadan. The chicks were randomly divided into two groups of 50 (Garlic - G) and 70 (No Garlic - NG) chicks. Chicks in Group G were fed ration containing $0.25 \%$ patented garlic-meal NG/P/2012/285 (Oladele, 2012) from day-old, while those in Group NG were fed plain ration and served as the control group. The garlic-meal is $70 \%$ raw garlic. The chicks were administered multivitamins in water for the first seven days of life. Infectious bursal disease vaccine was administered orally at 8 and 17 days of age, Newcastle disease vaccine, LaSota strain orally at 14 days of age while Newcastle disease vaccine, Komarov strain was administered intramuscularly at 9 weeks of age. Feed and water were always made available.

Induction of hepatotoxicity and nephrotoxicity: At 8 weeks of age, chickens in Group G were randomly divided into two sub-groups i.e., G1 and G2 of 25 each while those in Group NG were also divided into two sub-groups NG1 and NG2 of 45 and 25 chickens, respectively. A single known toxic dose of Acetaminophen (PANADOL ${ }^{\mathrm{R}}$, Glaxo SmithKline Consumer Nigeria Plc.), i.e., 300mg/kg (Gardner et al., 2012; Marmat et al., 2015) was administered orally to each chicken in sub-groups G1 and NG1 after the determination of their average weight as $0.4 \mathrm{~kg}$ i.e., $120 \mathrm{mg}$ in $1 \mathrm{ml}$ distilled water per bird. At 9 weeks of age, 20 chickens were isolated from NG1, designated as NG1g and garlic meal was included in their feed at $0.25 \%$.

Determination of Newcastle Disease antibody titer: Experimental chickens were bled (2ml each) at 4, 8 (prior to administration of Acetaminophen), 9, 11 and 14 weeks of age via jugular venipuncture using 21 guage needles and $5 \mathrm{ml}$ syringes. This is in addition to blood samples collected at day-old. Blood samples were dispensed into plain sample bottles and allowed to clot at room temperature. Sera were harvested into 1.5ml eppendorf tubes and Haemagglutination inhibition (HI) test was conducted as described by OIE (2012). Briefly, 50 $\mu$ l of 4HA units Newcastle disease inactivated virus (antigen) was dispensed into each well of U-bottom microtiter plates using two rows per serum sample. Fifty $\mu$ l of serum sample was then added to the first well of two rows of wells. Two-fold serial dilution was carried out from the first row to the last well (picking $50 \mu \mathrm{l}$ and transferring into the next well) and $50 \mu \mathrm{l}$ of $0.5 \%$ washed chicken RBC was dispensed into each well. The plate was incubated for 30 minutes at room temperature after which $\mathrm{HI}$ titers were read visually as the last well showing haemagglutination inhibition.

Serum enzymes and proteins assay: The chickens were bled at 8 weeks of age, prior to administration of Acetaminophen, as well as, at 2-, 7-, 14- and 21-days post administration. Sera were harvested and levels of aspartate aminotransferase, creatine kinase, creatinine, total protein and albumin from the different sub-groups were determined by spectrophotometry using Fortress Diagnostics ${ }^{\mathrm{R}}$ kits (Fortress Diagnostics Limited, Antrim, BT41 1QS, UK) and following manufacturer's manual. Globulin levels in serum samples were derived by deducting the values of albumin levels from those of total protein.

Clinical and pathological assessment: After the administration of acetaminophen, the chickens were monitored daily for clinical signs and mortality which were scored based on the degree of severity i.e., 1 for mild, 2 for moderate and 3 for marked (Oladele et al., 2018). Also, at 5, 8 and 14 days after the administration of acetaminophen, two chickens per group were euthanized by cervical dislocation (AVMA, 
2013). Gross pathological changes observed were noted, tissue samples from liver and kidney were also harvested into $10 \%$ formalin and sectioned for histopathological examination.

Statistical analysis: Mean and standard error of mean (SEM) for each parameter assessed was calculated per sub-group and analysed for significant differences between sub-groups using Analysis of Variance and Least significance difference method of multiple comparison at $p<0.05$.

\section{Results}

Ethics governing the use and conduct of experiments on animals were strictly observed, and the experimental protocol was approved by the Animal Care and Use Research Ethics Committee of the University of Ibadan (UI-ACUREC/App/2016/013).

Newcastle disease vaccinal immune response: At day-old, the chicks had a maternal antibody mean geometric titer (MGT) of $5.42 \pm 0.2\left(\log _{2}\right)$ which decreased to $3.1 \pm 0.39$ and $3.3 \pm 0.23$ in the no-garlic (NG) and garlic (G) groups, respectively, at 4 weeks of age (Fig.1). By 8 weeks of age MGT was 3.2 in all groups and decreased to a range of $2.1 \pm 0.16$ to $2.3 \pm 0.25$ by 9 weeks of age i.e., one-week postadministration of acetaminophen, with the $\mathrm{G} 1$ and $\mathrm{G} 2$ sub-groups having the highest titers with no significant difference ( $p>0.05)$ between them. By 11 weeks of age i.e., 3 weeks post-administration of acetaminophen, MGTs had increased to $7.13 \pm 0.38,8.14 \pm 0.31,7.6 \pm 0.23,8.0 \pm 0.25$ and $7.5 \pm 0.24$ in subgroups NG1, NG1 g, NG2, G1 and G2, respectively, while there were decreases to $3.75 \pm 0.28,4.0 \pm 0.3$, $5.4 \pm 0.31,6.3 \pm 0.23$ and $7.1 \pm 0.18$, respectively at 14 weeks of age.

Serum enzyme assay: The mean level of Aspartate aminotransferase (AST) in the serum of no-garlic group NG was $62.4 \pm 1.21$ while it was $52.4 \pm 1.1$ (Fig. 2) in the garlic group G pre-administration of acetaminophen, with the difference being significant $(p<0.05)$. At 2 days post-administration of acetaminophen (paa), mean levels were $83.7 \pm 7.5$ and $62.5 \pm 6.84$ in sub-groups NG1 and NG2 $(p<0.05)$, respectively, while they were $79.4 \pm 5.79$ and $75.1 \pm 7.85$ in sub-groups $\mathrm{G} 1$ and $\mathrm{G} 2$, respectively. At 7,14 and 21 days paa, AST levels ranged between $25.77 \pm 2.9$ (NG1) and 34.9 \pm 2.74 (G2), 39.6 \pm 4.79 (NG1g) and $57.2 \pm 2.96$ (NG1), as well as between $36.57 \pm 5.02$ (NG1g) and 65.3 \pm 2.35 (NG1), respectively.

The mean level of Creatine kinase (CK) in the serum of no-garlic group NG was $548.2 \pm 48.18$ while it was $590.2 \pm 40.82$ in the garlic group G pre-administration of acetaminophen (Fig. 3). At 2 days paa, mean levels were $699.2 \pm 52.3$ and $700.2 \pm 28.9$ in sub-groups $N G 1$ and NG2 respectively, while they were $712.8 \pm 22.02$ and $738.4 \pm 41.6$ in sub-groups $\mathrm{G} 1$ and $\mathrm{G} 2$, respectively. At 7 and 14 days paa, CK levels ranged between 765.0 \pm 10.7 (G1) and 532.0 \pm 34.31 (NG1) and, $401.0 \pm 29.0$ (NG1) and 547.0 \pm 12.12 (G2), respectively.

The mean level of Creatinine in the serum of no-garlic group NG was $0.42 \pm 0.02$ while it was $0.39 \pm 0.03$ in the garlic group $\mathrm{G}$ pre-administration of acetaminophen (Fig. 4). At 2 days paa, mean levels were $1.47 \pm 0.01$ and $1.31 \pm 0.06$ in sub-groups NG1 and NG2 respectively, while they were $1.44 \pm 0.01$ and $1.16 \pm 0.05$ in sub-groups G1 and G2, respectively. At 7-, 14- and 21-days pa, Creatinine levels ranged 
between 1.23 \pm 0.01 (G2) and 1.51 \pm 0.01 (NG1), 1.26 \pm 0.06 (G2) and 1.47 \pm 0.01 (NG1) and 1.44 \pm 0.13 (NG2) and $2.32 \pm 0.07$ (NG1), respectively.

Serum proteins assay: Pre-administration of acetaminophen, mean total protein concentration in the garlic group $G$ was $3.7 \pm 0.23 \mathrm{~g} / 100 \mathrm{ml}$, while it was $3.75 \pm 0.27 \mathrm{~g} / 100 \mathrm{ml}$ in the no-garlic group NG. At 2 days paa, mean values were $5.34 \pm 0.51$ and $5.83 \pm 0.51 \mathrm{~g} / 100 \mathrm{ml}$ in sub-groups NG1 and NG2 respectively, while they were $7.11 \pm 0.31$ and $7.05 \pm 0.3 \mathrm{~g} / 100 \mathrm{ml}$ in sub-groups $\mathrm{G} 1$ and $\mathrm{G} 2$, respectively. At 7-, 14- and 21days paa, total protein concentrations ranged between $3.09 \pm 0.15$ (NG1) and $3.79 \pm 0.32$ (NG2), 4.12 \pm 0.34 (NG2) and $5.64 \pm 0.42(\mathrm{G} 2)$ and $5.2 \pm 0.34(\mathrm{NG} 1 \mathrm{~g})$ and $6.45 \pm 0.22 \mathrm{~g} / 100 \mathrm{ml}(\mathrm{G} 2)$, respectively.

Pre-administration of acetaminophen mean serum albumin concentration in the garlic group $\mathrm{G}$ was $0.81 \pm 0.05 \mathrm{~g} / 100 \mathrm{ml}$, while it was $0.51 \pm 0.09 \mathrm{~g} / 100 \mathrm{ml}$ in the no-garlic group NG (Fig.5) At 2 days paa, mean values were $1.46 \pm 0.08$ and $1.58 \pm 0.17 \mathrm{~g} / 100 \mathrm{ml}$ in sub-groups NG1 and NG2 respectively, while they were $1.55 \pm 0.08$ and $1.81 \pm 0.08 \mathrm{~g} / 100 \mathrm{ml}$ in sub-groups $\mathrm{G} 1$ and $\mathrm{G} 2$, respectively. At 7-, 14- and 21-days paa, mean albumin concentrations ranged between $0.91 \pm 0.09$ (NG1) and $1.13 \pm 0.02$ (G2), $0.51 \pm 0.12$ (NG1g) and $0.81 \pm 0.07$ (G2) and $1.15 \pm 0.03(\mathrm{NG} 1)$ and $1.28 \pm 0.07 \mathrm{~g} / 100 \mathrm{ml}(\mathrm{G} 2)$, respectively.

Pre-administration of acetaminophen mean globulin concentration in the garlic group $\mathrm{G}$ was $2.89 \pm 0.24$ $\mathrm{g} / 100 \mathrm{ml}$, while it was $3.24 \pm 0.28 \mathrm{~g} / 100 \mathrm{ml}$ in the no-garlic group NG (Fig. 6). At 2 days paa, mean values were $3.76 \pm 0.44$ and $4.36 \pm 0.54 \mathrm{~g} / 100 \mathrm{ml}$ in groups NG1 and NG2 respectively, while they were $5.56 \pm 0.3$ and $5.25 \pm 0.31 \mathrm{~g} / 100 \mathrm{ml}$ in groups $\mathrm{G} 1$ and $\mathrm{G} 2$, respectively. At 7, 14 and 21 days paa, mean globulin concentrations ranged between 2.07 \pm 0.14 (NG1) and 2.74 \pm 0.29 (NG2), 3.45 \pm 0.41 (NG2) and 5.04 \pm 0.31 (G1) and $3.77 \pm 0.24$ (NG1) and $5.12 \pm 0.45(\mathrm{G} 1) \mathrm{g} / 100 \mathrm{ml}$, respectively.

Clinical assessment: Clinical signs observed were anorexia, dullness, paleness of combs and wattles, whitish diarrhoea and jaundice. These were visible from day 4 paa. Total scores of these clinical signs are presented in Fig. 7 as 7, 11 and 12 for NG1; 0, 1 and 1 for NG2; 0, 2, 0 for G1 and 0, 0, 0 for G2 at 5-, 8and 14-days paa, respectively, while NG1g had a total score of 8 at 14-days paa. Levels of anorexia in NG1 at 5-, 8- and 14-days paa were 2, 3 and 3 respectively, while $\mathrm{G} 1$ had a score of 1 at 8-days paa and NG1g had a score of 2 at 14-days paa. Anorexia was not observed in NG2 and G2 throughout the period of the experiment. Paleness was scored as 2, 3 and 2 at 5-, 8- and 14-days paa, respectively, in Group NG1, 1 at both 8- and 14-days paa in NG2, and 1 at 8-days paa in G1. Also, dullness was scored as 1, 3 and 3 in NG1 at 5-, 8- and 14-days paa, respectively, while it was 2 at 14-days paa in NG1g. Chickens in groups NG2, G1 and G2 did not exhibit dullness throughout the period of the experiment. NG1 exhibited watery-white feaces with a score of 2 at 14-days paa while yellowish discolouration of combs, beak and wattles, with a score of 2 was observed in one chicken at 5-, 8- and 14-days paa. Two mortalities were recorded in NG1g by day-14 paa.

Gross pathology: The carcasses of the two mortalities recorded were emaciated. They had swollen and congested liver, markedly engorged gall bladder and slightly swollen kidneys. From the euthanized cockerels, gross lesions observed were haemorrhages in skeletal muscle and hock joint, swollen and congested liver, engorged gall bladder and swollen kidneys. Total score for gross pathology was 10, 8, 8 
for NG1; 1, 0, 2 for NG2; 6, 3, 2 for G1 and 0, 0, 0 for G2 at 5-, 8- and 14-days paa, respectively, while NG1g had a total score of 6 at 14-days paa (Fig.8). Moderate (2) and mild (1) haemorrhages were observed in NG1 and G1, respectively, at 5- days paa (Fig. 9). In NG1, swollen and congested liver had scores of 3, 3 and 2 at 5-, 8- and 14- days paa, NG2 had a score of 1 at 14-days paa while G1 had a score of 1 in each of 5-, 8- and 14-days paa. Engorged gall bladder was marked (3) at 5-, 8- and 14-days paa in NG1 and mild (1) at 5- and 14-days paa in NG2 while it was marked (3) at 5-days paa and mild (1) at both 8- and 14-days paa in G1. NG1 had scores of 2, 2 and 3 for swollen kidneys at 5-, 8- and 14-days paa, respectively, while $\mathrm{G} 1$ had a score of 1 at both 5 - and 8-days paa.

Histopathology: Vacuolar degeneration and necrosis of hepatocytes in NG1 and coagulative necrosis of the hepatocytes mainly in $\mathrm{G} 1$, as well as infiltration of mononuclear cells (largely plasma cells) were observed at 5-, and 14-days paa (Fig. 10). Also, kidney tissues showed necrosis of tubular epithelial cells, glomerullar degeneration and infiltration of mononuclear cell consisting mainly of plasma cells (Fig. 11). Necrosis and cellular degeneration were more severe in NG1 than in G1 while cellular infiltration was more abundant in $\mathrm{G} 1$ than in NG1. On the contrary, no such lesions were observed in tissues from NG2 and G2. Liver and kidney sections obtained from chickens that were separated from NG1 and administered garlic i.e., NG1g, showed milder cellular necrosis and fewer mononuclear cell infiltration at 14-days paa and 6 days post-inclusion of garlic in feed (Fig. 12).

\section{Discussion}

This study investigated the probable protective effect of garlic against liver and kidney damage/injury in chickens. Conditions that affect the normal functioning of these two organs will have deleterious effect on health and productivity of poultry.

Newcastle disease vaccinal immune respone: Apart from Kupffer cells and T cells in the liver as immune cells, there are IgM bearing B cells (Seki et al., 2014) which produce immunoglobulins against ingested antigens that will eventually pass through the liver via the portal circulation. Since these experimental chickens were vaccinated against Newcastle disease via the oral route, assessment of vaccinal response as an indicator of liver function is therefore pertinent. Newcastle disease antibody assay showed that by 3 weeks paa (11 week-old), the no-garlic/acetaminophen group (NG1) had the least MGT of $7.13 \pm 0.38$ which was significantly lower $(p<0.05)$ than those of the other groups, while NG1g which is the sub-group of NG1 that was placed on garlic-meal from 1 week paa, had the highest MGT of $8.14 \pm 0.31$. Also, by 6 weeks paa (14 week-old), the garlic groups with and without adiministration of acetaminophen had the highest MGTs. This finding has again highlighted the immunomodulatory effect of garlic as earlier reported by Sumiyoshi (1997), Tang et al. (1997) and Oladele et al. (2018). Tang et al.(1997) reported that garlic activates NK cells and improves the function of Tcells. The liver is considered an organ of immunology (Racanelli and Rehermann, 2006) as such, any injury to it will reduce the immunocompetence of an animal, hence the decreased ND antibody response recorded in chickens in group NG1. Inspite of the induction of hepatotoxicity by acetaminophen, chickens in group G1 were able to mount a significantly higher level $(p<0.05)$ of ND antibody response than the NG1 group, indicating the 
probable potential of garlic to preserve the immune function of the liver in the event of an hepatotoxic condition. Also, the higher level of antibody response in the NG1g group which was placed on garlic-meal after the induction of hepatotoxicity shows that garlic has the potential to enhance regeneration of liver tissue after an injury as suggested by Memudu et al. (2015) with regards to testicullar cells.

Serum enzymes: Pre-administration of acetaminophen, AST level was significantly higher $(p<0.05)$ in the no-garlic groups than in the garlic groups with no corresponding increase in CK levels, an indication that the AST in serum was predominantly from the liver and not from the muscles (Doneley, 2011). The lower level in the garlic group shows an enhanced cellular integrity of hepatocytes by garlic. An earlier study by Memudu et al.(2015) showed increased proliferative activity with retention of testicular integrity and increased testosterone levels in Sprague-Dawley rat upon ingestion of garlic cloves. By 2 days paa, serum AST levels in the acetaminophen groups i.e. NG1 and G1 were higher than in the corresponding control groups NG2 and $G 2$, respectively, with NG1 having significantly higher $(p<0.05)$ level than $G 1$. Inspite of these differences in serum AST levels, CK levels were not significantly diffferent. According to Doneley (2011), an elevated AST level with normal CK level is an indication of hepatocellular damage. It is therefore apparent that there was leakage of AST from hepatocytes at this time, an indication of liver injury which was more severe in the no-garlic group (NG1). By 14- and 21-days paa, serum AST levels were significantly higher $(\mathrm{p}<0.05)$ in the no-garlic groups (NG1 and NG2) than the garlic groups (G1 and G2). However, serum CK levels were lower, the difference between NG1 and G2 being significant $(p<0.05)$. Serum AST levels within each of the garlic and no-garlic groups showed no significant difference with respect to acetaminophen administration from 14 days paa. It is known that drug-induced liver injury is an acute condition such that elevation of liver enzymes occurs soon after exposure to toxic doses (David and Hamilton, 2010) just as detected by Marmat and Rathore (2015) 24 hours post administration of toxic doses of acetaminophen to broilers chicks. Thus the non-dectection of elevated AST levels in acetaminophen groups NG1 and G1 by 14 days paa. It is worthy of note that experimental chickens that were separated from the no-garlic/acetaminophen group (NG1) and placed on garlic-meal from one week paa (NG1g), had significantly lower $(p<0.05)$ level of AST when compared with NG1 by 14 - and 21 -days paa. This signals the restorative ability of garlic on damaged liver cells as suggested by Kodera et al. (2002), Bozin et al. (2008) and Memudu et al. (2015).

Serum creatinine levels were about equal in garlic and no-garlic groups pre-administration of acetaminophen. However, from 2- to 14-days paa, levels were significantly higher $(p<0.05)$ in acetaminophen groups NG1 and G1 than in their respective control groups NG2 and G2, and within the acetaminophen groups, NG1 had significantly higher $(p<0.05)$ levels than $\mathrm{G} 1$. The result at 21-days paa was also similar except that level in G1 was not significantly higher $(p>0.05)$ than NG2 and G2. It is largely believed that creatinine has limited diagnostic value in avian species because a large proportion of creatine is excreted in urine before it is converted to creatinine such that levels in plasma are low (Doneley, 2011). However, the proportion left in plasma is usually excreted by glomerular filtration and reabsorbed in the tubules such that plasma concentrations are constant. Thus, reduction in glomerular filtration can lead to an increased creatinine concentration (Lierz, 2003). The increased serum creatinine levels recorded for the acetaminophen groups with or without garlic pre-treatment is believed to be due to 
acute kidney injury induced by the toxic dose of acetaminophen administered. The significantly higher $(p<0.05)$ levels in no-garlic group NG1 than the garlic group G1 through out the study period and the significantly lower $(p<0.05)$ levels in NG1g group than NG1 group at 14- and 21-days paa, signals reduced excretion by the kidney due to injury and a preservative or protective effect of garlic on the kidney tissue against toxic effects of acetaminiphen, respectively as opined by Kodera et al. (2002), Bozin et al. (2008) and Memudu et al. (2015).

Serum proteins: Assay for serum proteins in the experimental chickens showed fairly uniform levels of total protein, albumin and globulin between garlic and no-garlic groups pre-administration of acetaminophen. However, from 2- to 21-days paa, levels in the no-garlic/acetaminophen group NG1were mostly significantly lower $(p<0.05)$ than in the garlic/acetaminophen group $\mathrm{G} 1$. Also, the two garlic groups $\mathrm{G} 1$ and $\mathrm{G} 2$ almost consistently had higher serum protein levels than the no-garlic groups NG1 and NG2. No-garlic/acetaminophen group (NG1) constantly had significantly lower $(p<0.05)$ levels than the garlic/acetaminophen group (G1). The liver is the site of production of plasma proteins, albumin, fibrinogen, lipoproteins and a variety of alpha and beta globulins (Busher, 1990; Hochleithner et al., 2005). According to Singh et al. (2011), reduction in total protein concentration and particularly, albumin is an indication of hepatotoxicity as observed in chickens in NG1. However, the significantly higher concentrations recorded for garlic/acetaminophen group G1 further emphasizes the protective effect of garlic on the liver. In addition, the comparatively higher serum albumin concentrations observed in the garlic/no-acetaminophen group G2 could be due to increased liver synthesis in response to availability of amino acids from the portal blood (Busher, 1990). Oladele et al. (2012) had earlier reported increased absorptive capacity of the small intestine of broilers that were served garlic-meal as an additive in feed. Hypoproteinaemia as recorded for NG1 could also be due to kidney damage causing loss of globulins (Busher, 1990).

Clinical assessment: Clinical signs of toxicity were observed from 4-days paa. Clinical assessment of the experimental chickens showed mild to marked dullness, anorexia and paleness in the NG1 (nogarlic/acetaminophen) group from 5-to 14-days paa, G1 (garlic/acetaminophen) group was mildly anorexic and pale at only 8-days paa while the NG1g (no-garlic/acetaminophen, subsequemtly placed on garlic-meal) showed improved anorexia and moderate dullness at 14-days paa. An earlier study on the lethal doses of acetaminophen in broilers by Marmat et al. (2015) reported dullness after four hours of administering 1500 and $1750 \mathrm{mg} / \mathrm{kg}$ body weight acetaminophen. According to Hochleithner et al. (2005), clinical signs of hepatic failure in birds are variable and can range from mild inappetence and inactivity, to acute haemorrhage and death. Moderate watery faeces (polyuria) and jaundice were also observed in the NG1 group which were absent in other groups. Jaundice is an uncommon condition in avian species as they lack biliverdin reductase and glucuronyl transferase, the enzymes responsible for the conversion of biliverdin to bilirubin. As such, biliverdin is the primary bile pigment which gives the avian bile its characteristic green colour (Hochleithner et al., 2005; Doneley, 2011). However, a study in broilers with gross hepatic bile duct lesions, traced the yellow colour of the pericardium and carcass to bilirubin (Mizobe et al., 1997). Hochleithner et al. (2005) explained that bacterial reduction may be responsible for the degradation of avian biliverdin to bilirubin in some cases. 
Gross pathology: Swollen and congested liver, engorged gall bladder, swollen kidneys and petechial haemorrhages in skeletal muscles and joints surfaces were the gross pathology observed in acetaminophen groups with and without garlic pre-treatment. However, lesions were more severe in nogarlic group (NG1) than in garlic group (G1). Hepatomegaly as observed in chickens administered acetaminophen in this study is believed to be due to both inflammation as a result of innate response (Wang et al., 2015) and swelling of hepatocytes due to the cytotoxicity. These are known to cause occlusion of the biliary system and increase retention of bile i.e., cholestasis (Doneley, 2011), as evidenced by engorged gall bladders observed in chickens in groups NG1 and G1. Haemorrhages observed in the groups of chickens that were administered acetaminophen could be due to inadequate production of clotting factors by the liver (Doneley, 2011; Mammen, 1992). Swollen kidney as a gross expression of acetaminophen toxicity had earlier been reported by Elhabib et al. (2007). The milder expression of these gross pathological lesions in chickens in the garlic/acetaminophen group (G1) once again indicates the protective effect of garlic on liver and kidney cells.

Histopathology: Histopathological lesions observed i.e., vacuolar degeneration and coagulative necrosis of hepatocytes, degeneration, and necrosis of tubular epithelium in kidneys and mononuclear cell infiltrations into both organs are evidence of hepato- and nephrotoxicity induced by acetaminophen as earlier reported by Blakely and McDonald (1995), Elhabib et al. (2007) as well as Marmat and Rathore (2015). The observation of more mononuclear cells infiltrating the liver and kidneys of chickens in G1 than NG1 indicates an enhanced immune response in the garlic groups, more so that the cells were largely plasma cells. The NG1g group that were served garlic-meal from 8 days paa and sampled at 14 days paa showed milder necrosis and reduced inflammatory cells infiltration signaling tissue regeneration. In as much as the liver and kidney have innate capacity for regeneration post damage (Echols, 2007; Hochleithner et al., 2005), the faster recovery by the NG1g group than the NG1 group is believed to be due to the garlic-meal feed additive.

Mechanism of toxicity and protection by garlic: The mechanism of toxicity induced by overdose of acetaminophen is via cytochrome P-450 mediated oxidative metabolism to a highly reactive intermediate metabolite, N-acetyl-p-benzoquinone iminine (NAPQI), an electrophile and an oxidizing agent which is normally detoxified by glutathione peroxidase. However, when in excess this metabolite covalently binds with intracellular protein leading to cellular necrosis (Fontana, 2008; Gibson et al., 1996). Some diseases of poultry species such as aflatoxicosis, simulate acetaminophen toxicity. Aflatoxin B1 is known to be strongly hepatotoxic and carcinogenic (Yuns et al, 2011). It undergoes a biological change into a number of metabolites which bind DNA and RNA, reduce protein synthesis and decrease both antibody-mediated and cell-mediated immunity. Liver, kidney, and spleen becomes enlarged and fat accumulates in liver cells as clear vacuoles in high-dose exposure. Small haemorrhages also occur due to decreased synthesis of clotting factors (Vegad, 2008). Yuns et al. (2011) reported that cytochrome P-450 enzymes in the liver and other tissues convert aflatoxin B1to metabolites which covalently bind DNA and other intracellular proteins causing toxicity and cancer. 
The protective effect of garlic on cells is believed to be via its antioxidant components i.e., flavonoids and sulpur-containing compounds i.e., diallyl sulfides, trisulfide and allylcysteine (Bozin et al., 2008; Kodera et al., 2002). A study by Jeong et al. (2013) investigated the antioxidant activities and neuron-like PC 12 cell protective effects of solvent fractions from aged garlic extracts. They reported that ethyl acetate fractions showed the highest amyloid beta $(A \beta)$ protein radical scavenging activity and malondialdehyde inhibitory effect and concluded that these fractions showed protection against $A \beta$-induced neurotoxicity. Butt et al. (2009) had earlier reported that garlic components or formulations can scavenge free radicals, protect membranes from damage and maintain cell integrity. Also, Memudu et al. (2005) demonstrated the retention of testicular integrity and testosterone levels as a result of ingestion of garlic cloves by SpragueDawley rats and inferred that garlic has proliferative and restorative potentials on cells. According to Fanelli et al. (1998) and Siegers et al. (1999), the chemo-preventive potential of garlic has been attributed to the presence of several bioactive organosulfur compounds which might act as antioxidants.

\section{Conclusion}

Thus, the inclusion of garlic in the feed of chickens in this study which enhanced antibody response to Newcastle disease vaccination, reduced serum AST and creatinine levels, increased serum protein production and reduced clinical signs and pathological lesions associated with toxic dose of acetaminophen as well as, the reversal of these toxic effects on the liver and kidney shows the potential of garlic in protection against hepatorenal damage or injury. It is therefore recommended that the inclusion of this garlic-meal in feed for chickens at a rate of $0.25 \%$ could be beneficial in protection against diseases and conditions that impair the health and functions of the liver and kidney.

\section{Declarations}

Funding: No funding was received for conducting this study.

Conflicts of interest: The authors have no conflicts of interest to declare that are relevant to the content of this article.

Availability of data and material: All data generated or analysed during this study are included in this published article [and its supplementary information files.

Ethics approval: This study was approved by the Animal Care and Use Research Ethics Committee of the University of Ibadan (UI-ACUREC/App/2016/013).

Acknowledgement: Authors appreciate the assistance provided by Mr. Ini Akpan in caring for the experimental chickens and Mrs lyabo A. Adetiba for providing laboratory assistance.

\section{Author contributions}


All authors contributed to the study conception and design. Material preparation, data collection and analysis were performed by Omolade Oladele, Oluwaseun Esan and Adetolase Bakre. The first draft of the manuscript was written by Omolade Oladele and all authors commented on previous versions of the manuscript. All authors read and approved the final manuscript.

\section{References}

Abdel-Aziz SM, Aeron A, Kahil T (2016) Health benefits and possible risks of herbal medicine. In: Garg N, Abdel- Aziz S, Aeron A (eds) Microbes in food and health, Springer International Publishing, Switzerland, pp 97-116.

Adibmoradi M, Navidshad B, Saif DJ, Royan M (2006) Effect of dietary garlic meal on histological structure of smallintestine in broiler chickens. J Poult Sc 43:378-83.

AVMA (2013) Guidelines for the euthanasia of animals. American Veterinary Medical Association. Illinois.

Bakre AA, Oladele OA, Esan 00 (2020) Garlic enhances cellular immune response via increased secretion of IFNy in Chickens. Alex J Vet Sci 66(2): 74-77.

Blakely P, McDonald BR (1995) Acute renal failure due to acetaminophen ingestion: a case report and review of literature. J Am Soc Nephrol 6(1): 48-53.

Bozin B, Dukic NM, Samojlik I, Anakov GT, Igic R (2008) Phenolics as antioxidants in garlic (Allium sativum L., Alliceae). Food Chem 111(4): 925-929.

Busher JT (1990) Serum albumin and globulin. In: Walker HK, Hall WD, Hurst JW (eds) Clinical Methods: Thehistory, physical and laboratory examinations, Butterworths, Boston, pp 497-499.

Butt MS, Sultan MT, Butt MS, Iqbal J (2009) Garlic: Nature's protection against physiological threats. Crit Rev Food Sci Nutr 49(6):538-551.

Davegowda G (1996) An application of Herbal medicines for improved poultry production. In: Proceedings of XX World Poultry Congress. World's Poultry Science Association. New Delhi, India.

Davegowda G, Murthy TNK (2005) Mycotoxins: Their effects in poultry and some practical solutions. In: Diaz DE (ed) The mycotoxin blue book, Nottingham University Press, Nottingham, UK, pp 25-26.

David S, Hamilton JP (2010) Drug-induced liver injury. US Gastroenterol Hepatol Rev 6:73-80.

Deepak M, Dipankar G, Prasanth D, Asha MK, Amit A, Venkatraman BV (2002) Tribulosin and $\beta$-sitosterolD glucoside, the anthelminthic principles of Tribulus terrestris. Phytomedicine 9: 753-756.

Doneley B (2011) Avian medicine and surgery in practice: Companion and aviary birds. Manson Publishing Limited, UK. 
Echols SM (2007). Evaluating and treating the kidneys. In: Clinical avian medicine - II. Harrison GJ, Lightfoot T (eds) Spix Publishing, USA, pp $451-490$.

Elhabib EM, Homeida MMA, Adam SEl (2007) Effects of combined paracetamol and Cuminum cyminum or Niegalla sativa use in Wistar rats. J Pharmacol Toxicol 2(7): 653-659.

Fanelli SL, Castro GD, de Toranzo EG, Castro JO (1998) Mechanisms of the preventive properties of some garlic components in the carbon tetrachloride-promoted oxidative stress. Diallyl sulphide; diallyl disulfide; allyl mercaptan and allyl methylsulphide. Res Commun Mol Pathol Pharmacol 102(2):163-174.

Fontana RJ (2008) Acute liver failure including acetaminophen overdose. Med Clin North Am 92(4):761794.

Gardner CR, Mishin V, Laskin JD, Laskin DL (2012) Exacerbation of acetaminophen hepatotoxicity by the anthelmintic drug Febendazole. Toxicol Sci 125(2): 607-612.

Ghazanfari, T., Hassan, Z., Ebrahimi, M. 2002. Immunomodulatory activity of a protein isolated from garlic extracton delayed type hypersensitivity. Int Immunopharmacol 2, 1541-1549.

Gibson JD, Pumford NR, Samokyszyn VM, Hinson JA (1996) Mechanism of acetaminophen-induced hepatotoxicity: covalent binding versus oxidative stress. Chem Res Toxicol 9(3): 580-585.

Gill C (2000) Botanical Feed Additives. Feed Int April: 14-17.

Hochleithner M, Hochleithner C, Harrison LD (2005) Evaluating and treating the liver. In: Harrison GJ, Lightfoot T (eds) Clinical avian medicine-Volume I, Spix Publishing, USA, pp 441- 450.

Jahan MS, Sabina R, Rubaiyat A (2008) Alkaline pulping and bleaching of Acacia auriculiformis grown in Bangladesh. Turk J Agric For 32: 339-347.

Jeong JH, Jeong HR, Jo YN, Kim HJ, Shin JH, Heo HJ (2013) Ameliorating effects of aged garlic extract against $A \beta$-induced neurotoxicity and cognitive repair. BMC Complement Alt Med 13:268.

Kodera Y, Suzuki A, Imada O, Kasuga S, Sumioka I, Kanezawa A, Taru N, Fujikawa M, Nagae S, Masamoto K, Maeshige K, Ono K (2002) Physical, chemical and biological properties of S-allyl cysteine, an amino acid derivative from garlic. J Agric Food Chem 50(3): 622-632.

Konjufca VH, Pesti GM, Bakalli RI (1997) Modulation of cholesterol levels in broiler meat by dietary garlic and copper. Poult Sci 76:1264-1271.

Lierz M (2003) Avian renal disease: pathogenesis, diagnosis, and therapy. Vet Clin Exot Anim 6:29-55.

Mammen EF (1992) Coagulation abnormalities in liver disease. Haematol Oncol North Am 6(6): 12471257. 
Marmat S, Rathore HS (2015) Hepatorenal toxicity of paracetamol (Acetaminophen) in broiler chicks at lethal dose. Ind J Pure App Biosci 30(2):117-122.

Marmat S, Qureshi TN, Rathore HS (2015) Lethal doses of acetaminophen (paracetamol)for young broiler chicks. Ind J Pharm Sci Res 5(1): 23-26.

Manzanilla EG, Baucells F, Kamel C, Morales J, Perez JF, Gasa J (2001) Effects of plantextracts on the performance and lower gut microflora of early weaned piglets. J Anim Sci Suppl 1:473.

Memudu AE, Akinmade ID, Ogundele OM (2015) Retention of testicular integrity and testosterone levels upon ingestion of garlic cloves (Allium sativum) in Sprague-Dawley rat. Asian Pac J Trop Biomed 5(4): 319-323.

Mizobe M, Kondo F, Kumamoto K, Kanda Y, Seguchi H (1997) High-performance liquid chromatographic analysis of bilirubin and biliverdin from jaundiced broilers. J Vet Med Sci 59(8):677-680.

OIE (2012) Manual of diagnostic tests and vaccines for terrestrial animals. World Organization for Animal Health. Paris.

Oladele OA (2012) Organic growth promoter for poultry. Nigerian patent. Patent No. NG/P/2012/285. Federal Ministry of Commerce and Industry, Trademarks, Patents and Design Division, Patents Branch, Federal Secretariat, Abuja. Nigeria.

Oladele OA, Bakare H (2011). Effects of garlic (Allium sativum) on growth performance and vaccinal immune response in commercial broilers. J Commonwlth Vet Assoc 27(2): 243-247.

Oladele OA, Emikpe BO, Hauwa B (2012) Effects of dietary garlic (Allium sativum) supplementation on body weight and gut morphometry of commercial broilers. Int J Morphol 30(1): 238-240.

Oladele OA, Esan OO, Adetiba IA, Akpan IL, Adewale OM (2018) Haematological, serum biochemical and immunological changes associated with the inclusion of garlic (Allium sativum L.) in the diet of commercial layer chickens. J Poult Res 15(2): 8-15.

Onu PN (2010) Evaluation of two herbal spices as feed additives for finisher broilers. Biotech Anim Husbandry 26 (5-6):383-392.

Racanelli V, Rehermann B (2006) The liver as an immunological organ. Hepatol 43(2 Suppl. 1): s54-62.

Seki S, Ikarashi M, Kinoshita M, Nakashima M, Nokoshima H (2014). New findings about liver Kupffer cells/macrophages, B cells and their functions. J Hepat Res 1(1):1003.

Siegers CP, Steffen B, Robke A, Pentz R (1999) The effects of garlic preparations against human tumor cell proliferation. Phytomedicine 6:7-11.

Singh A, Bhat TJ, Sharma OP (2011) Clinical biochemistry of hepatotoxicity. Clin Toxicol S4, 001: 1-19. 
Sivam GP (2001) Protection against Helicobacter pylori and other bacterial infection by garlic. J Nutr 13:1106S-8S.

Sumiyoshi H (1997) New pharmacological activities of garlic and its constituents (Review). Folia Pharma Japonica 110 (Suppl. I): 93-97.

Tang Z, Sheng Z, Liu S, Jian X, Suin K, Yan M (1997) Preventive function of garlic on experimental oral precancer and its effect on natural killer cells. Bull Hum Med Univ 22(3): 246- 8.

Toplak GK Zagreb, Mozaik Kniga (2005) Domace lekovito bilje. In: Health benefit of garlic.www.herbcyclopedia.com/item/health-benefits-of-galic-2. pp 50-51. Retrieved on 6 July, 2016.

Vegad JL (2008) Poultry diseases: a guide for farmers and poultry professionals. International Book Distribution Company, Lucknow, India.

Wang X, Zhang L, Jiang Z (2015) T-helper cell-mediated factors in drug-induced liver injury. J App Toxicol 35(7): 695-700.

Yuns AW, Razzazi-Fazeli E, Bohm J (2011) Aflatoxin B1 in affecting broiler performance immunity and gastrointestinal tract: A review of history and contemporary issues. Toxins 3: 566-590.

Figures

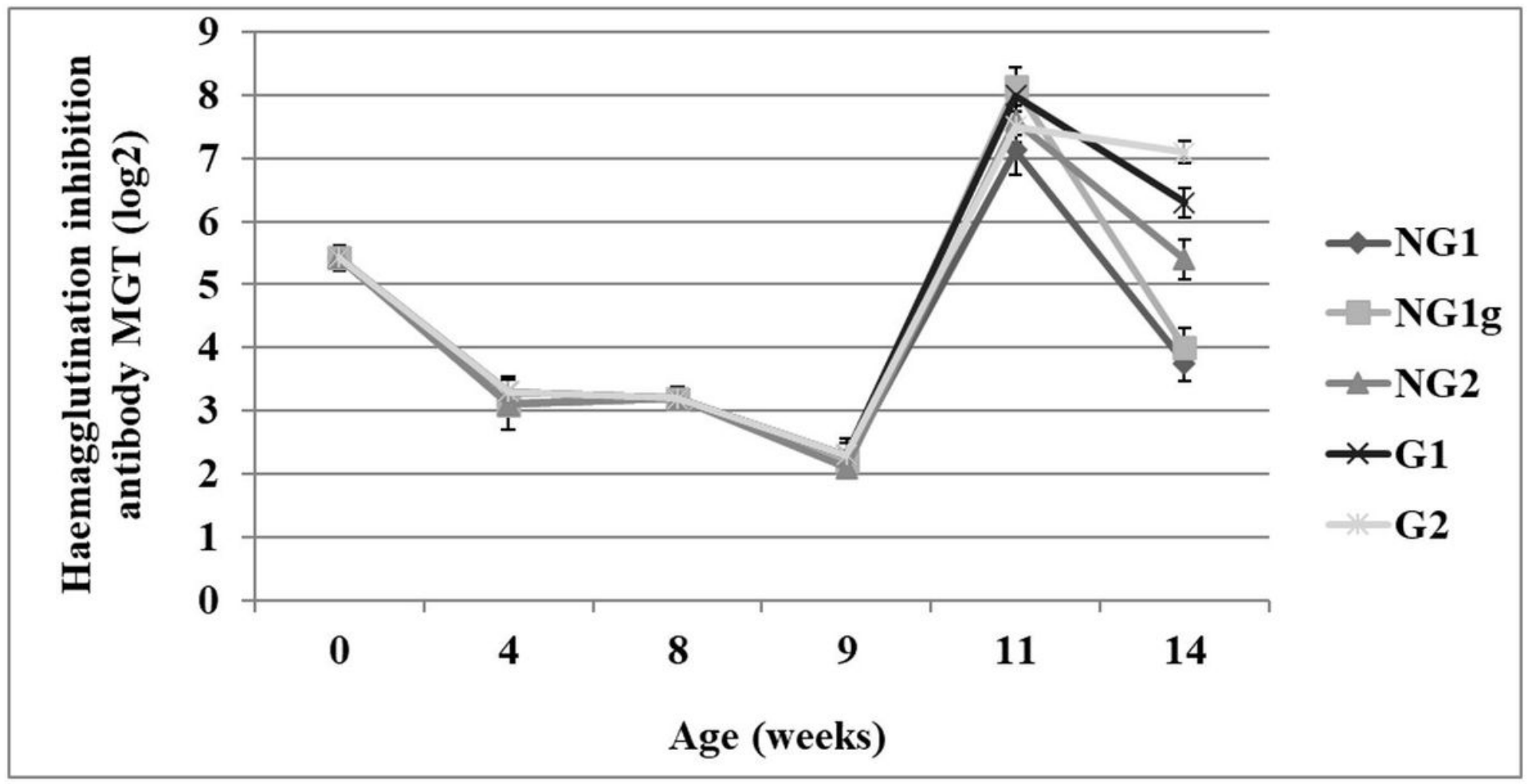

Figure 1 
Newcastle disease haemagglutination inhibition antibody titers in cockerels on garlic feed additive and administered acetaminophen

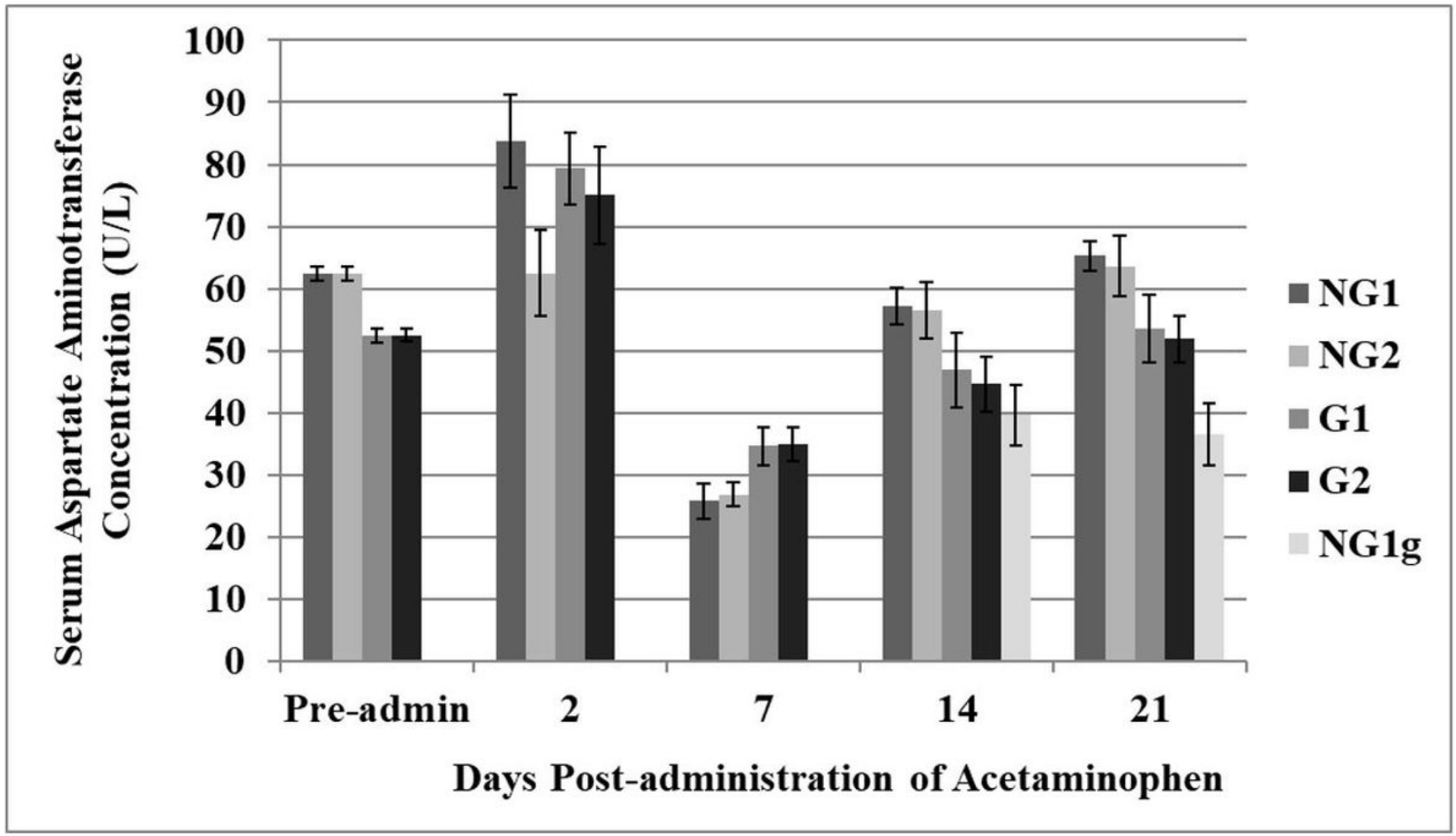

Figure 2

Serum Aspartate aminotransferase concentrations in cockerels pre- and post-administration of toxic dose of acetaminophen 


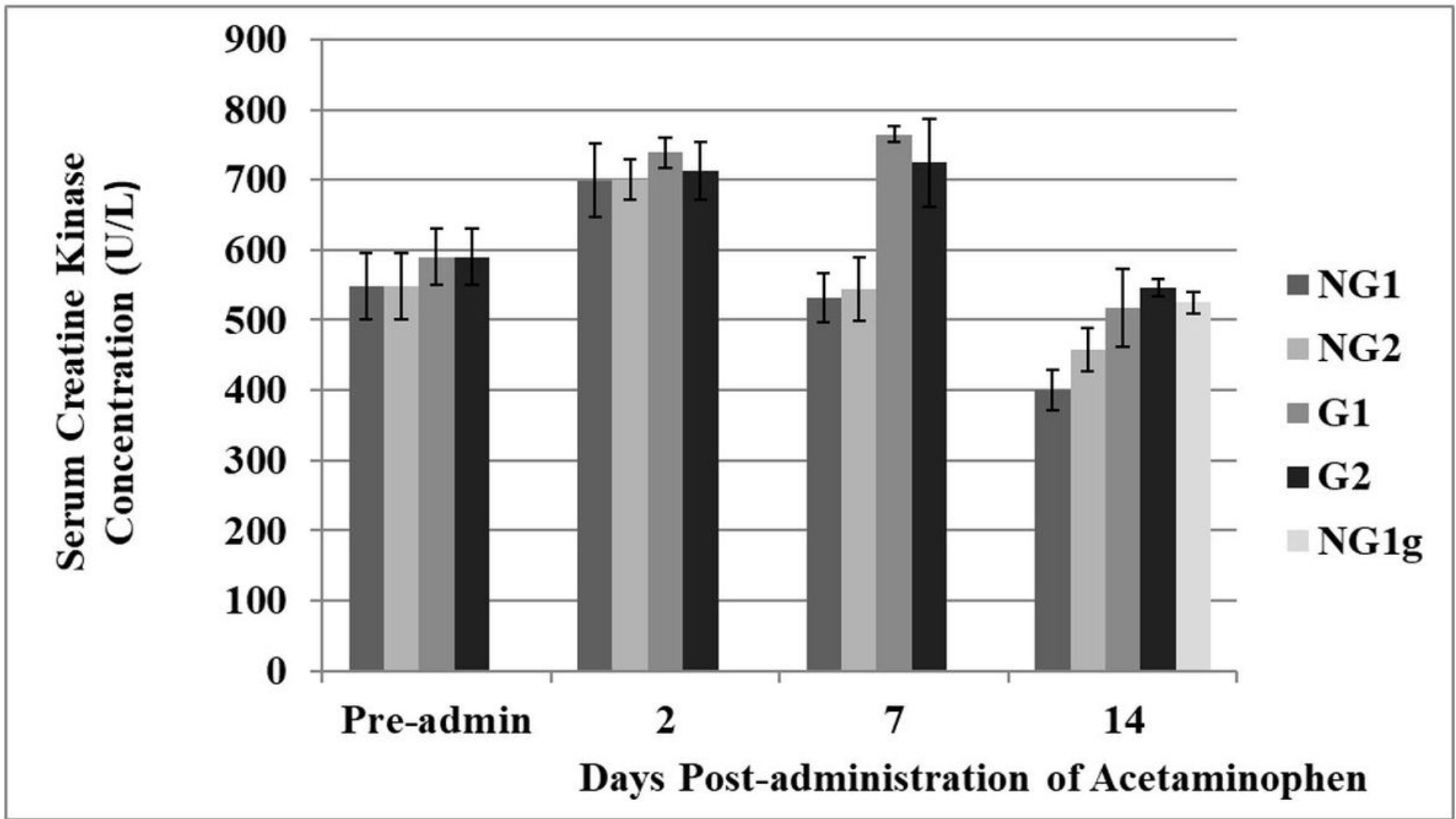

Figure 3

Serum Creatine kinase concentrations in cockerels pre- and post-administration of toxic dose of acetaminophen 


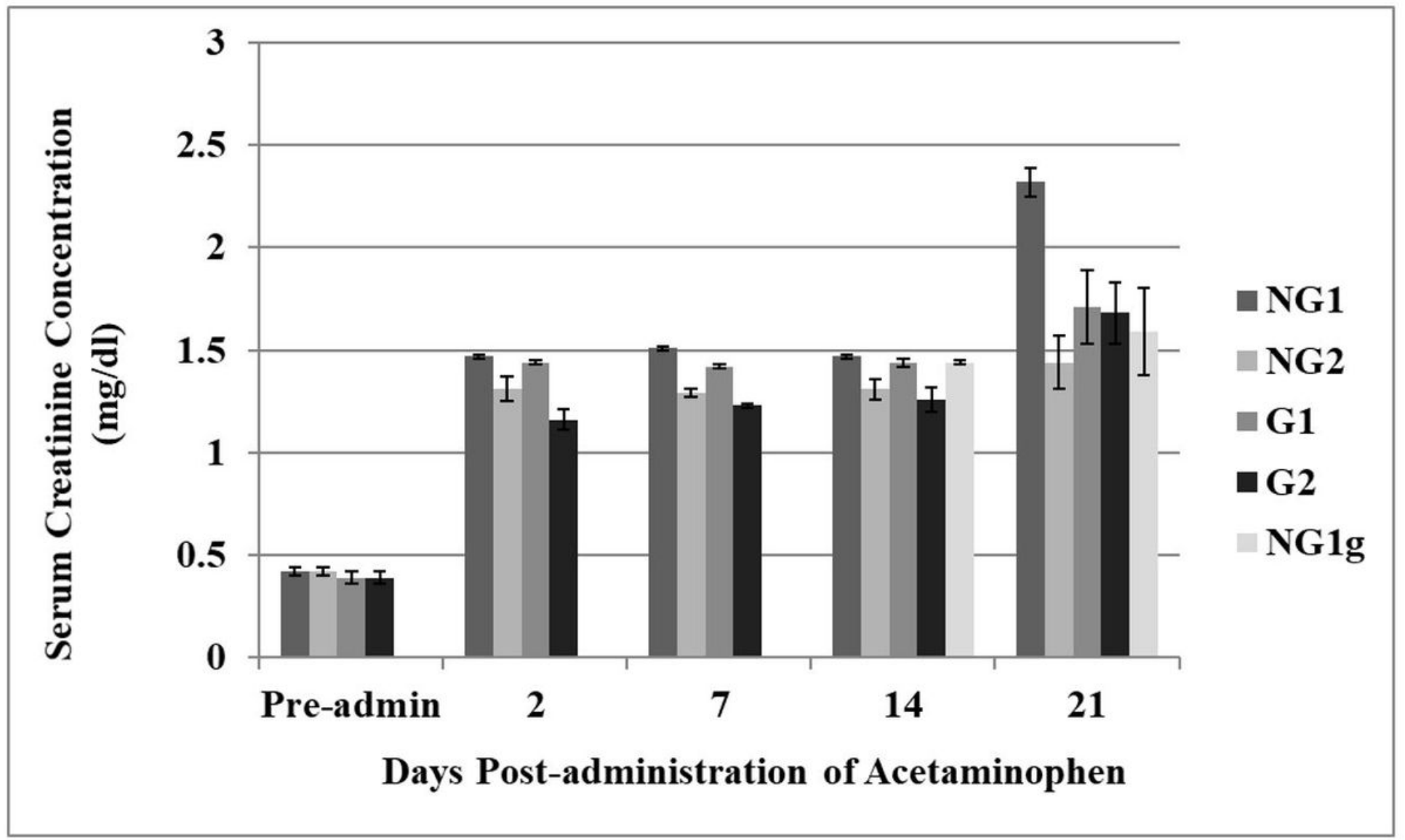

Figure 4

Serum Creatinine concentration in cockerels pre- and post-administration of toxic dose of acetaminophen 


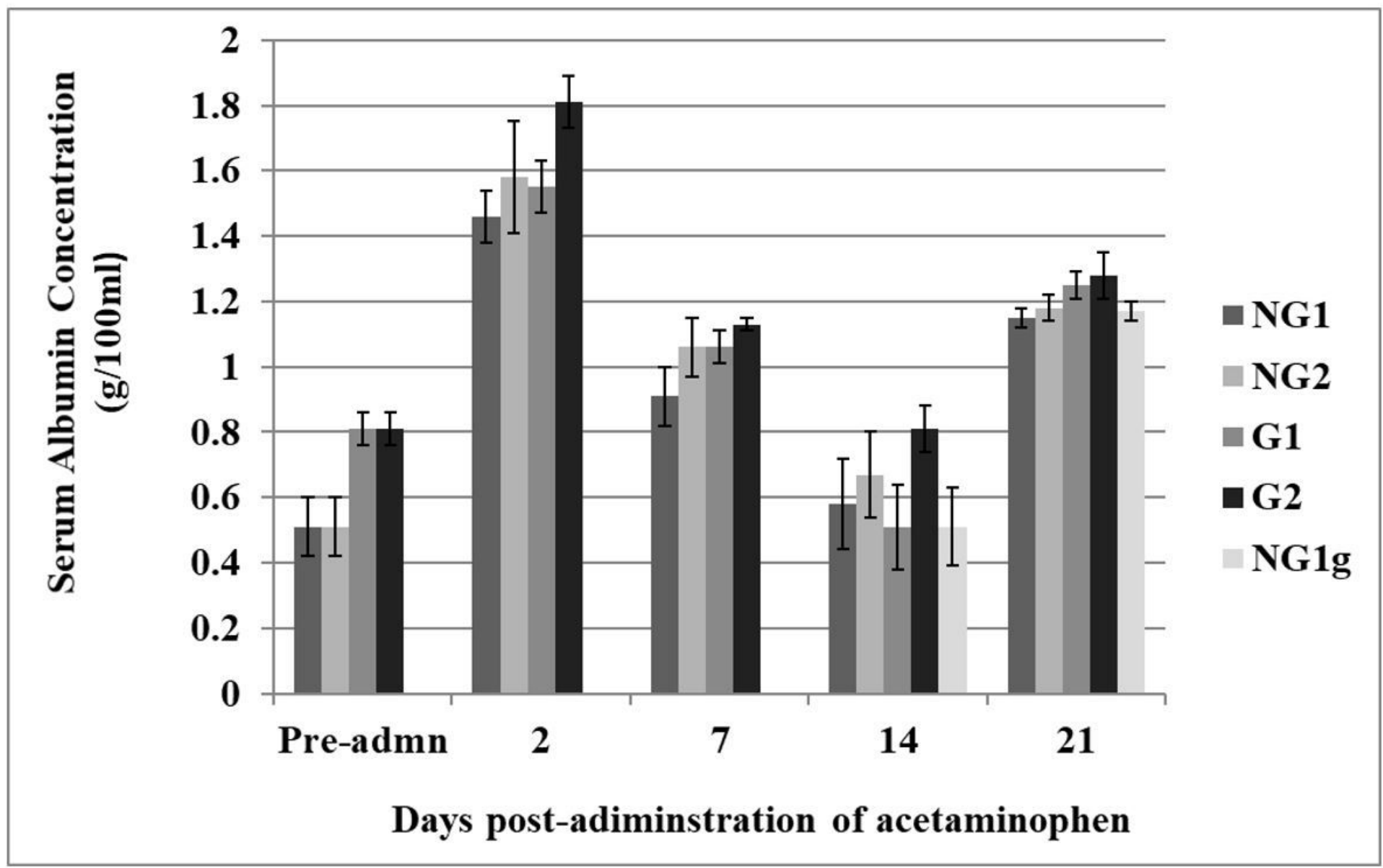

Figure 5

Serum albumin concentrations in cockerels pre- and post-administration of toxic dose of acetaminophen

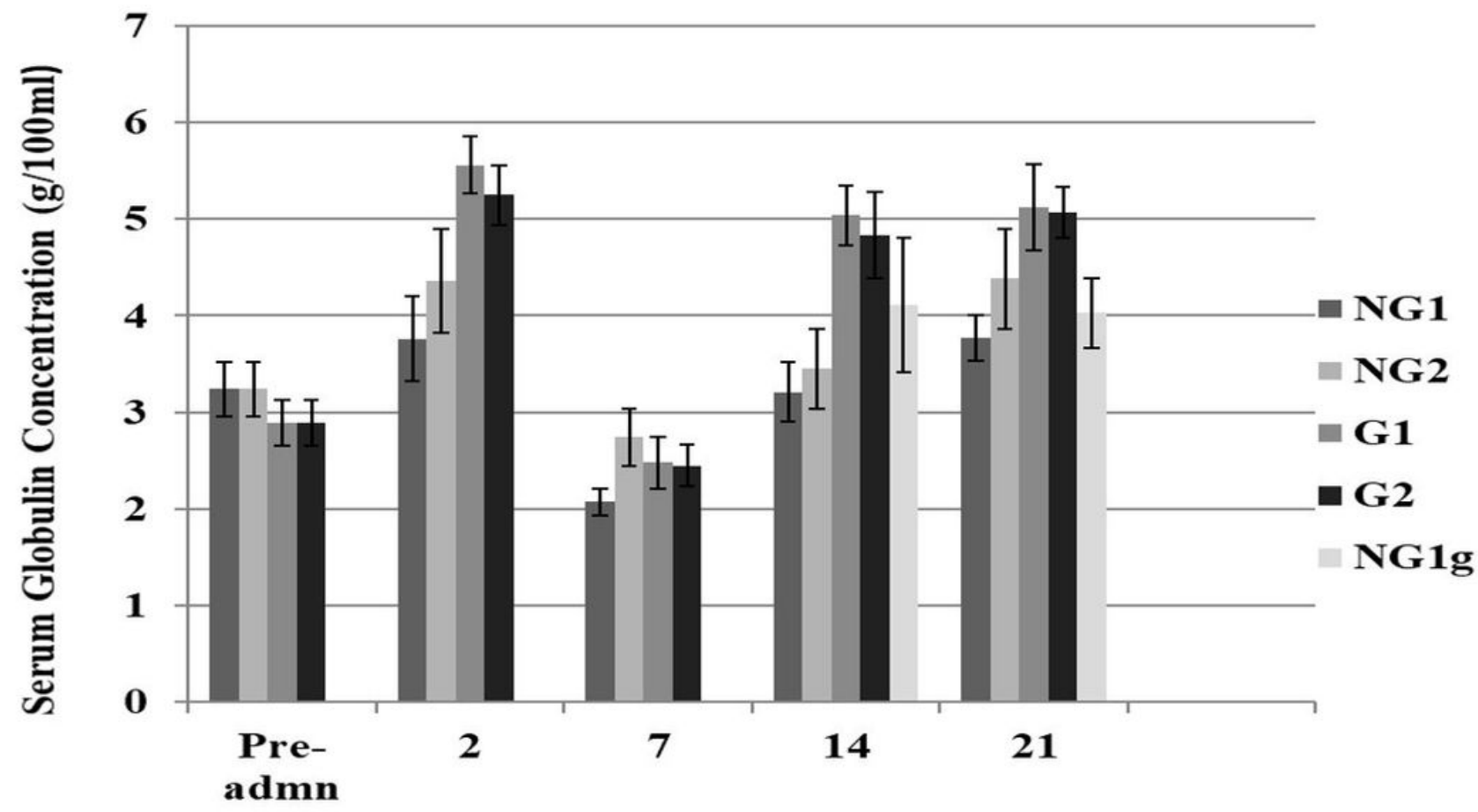

Days post-administration of acetaminophen 
Figure 6

Serum globulin concentrations in cockerels pre- and post-administration of toxic dose of acetaminophen

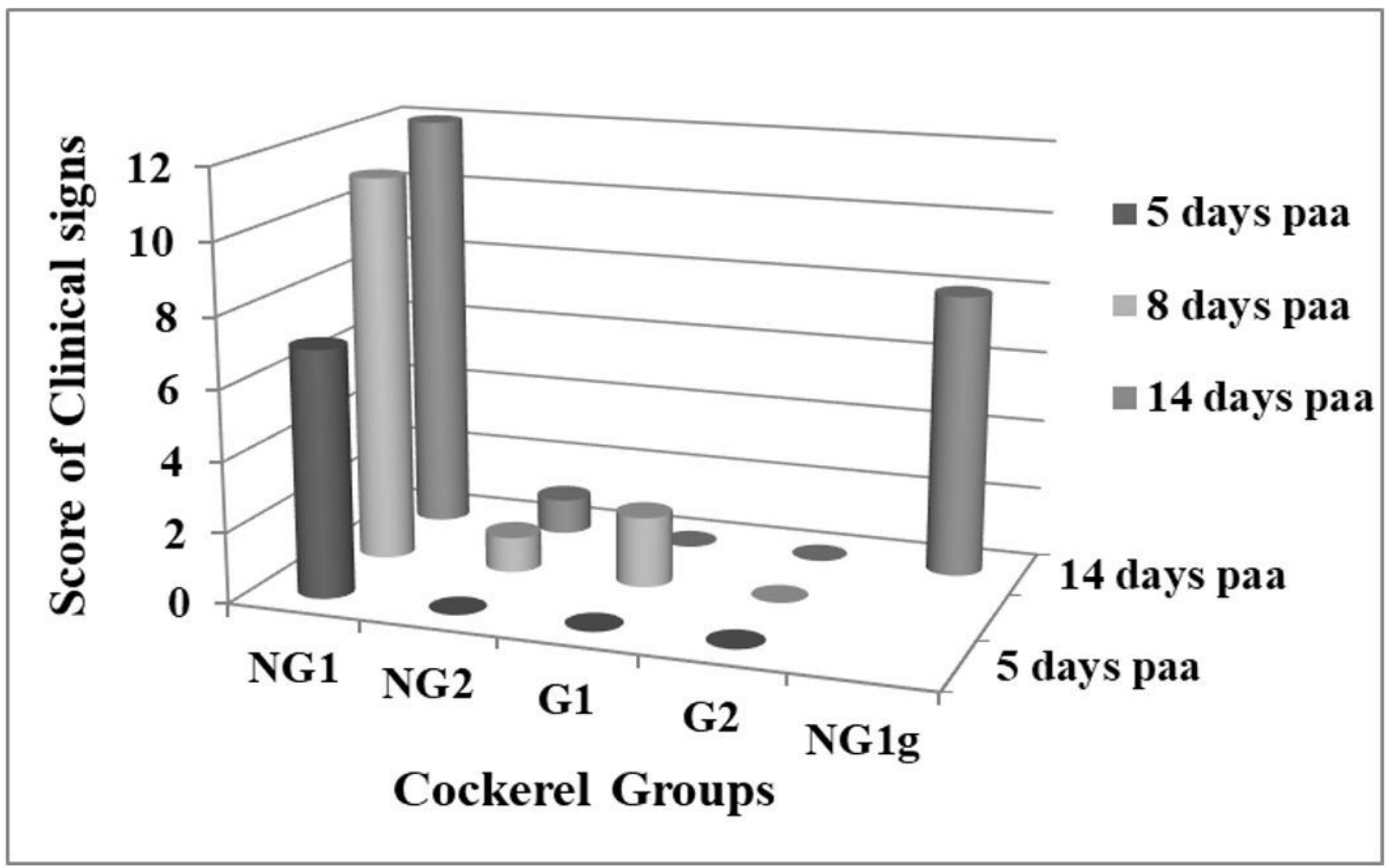

Figure 7

Total score of clinical signs observed in cockerels on garlic meal feed-inclusion post-administration of acetaminophen. 


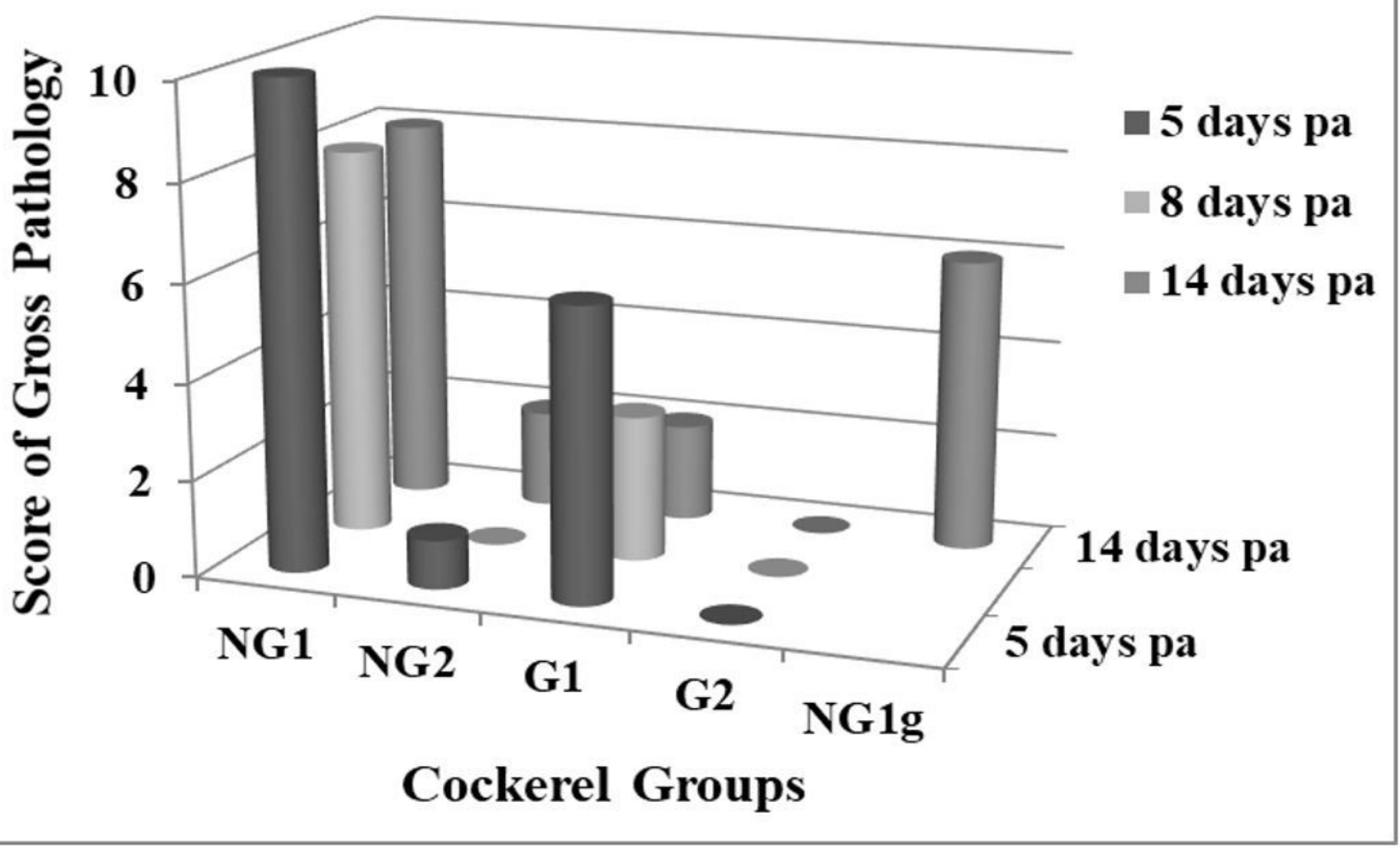

Figure 8

Total score of gross pathological lesions observed in cockerels on garlic meal feed-inclusion, postadministration of acetaminophen. 

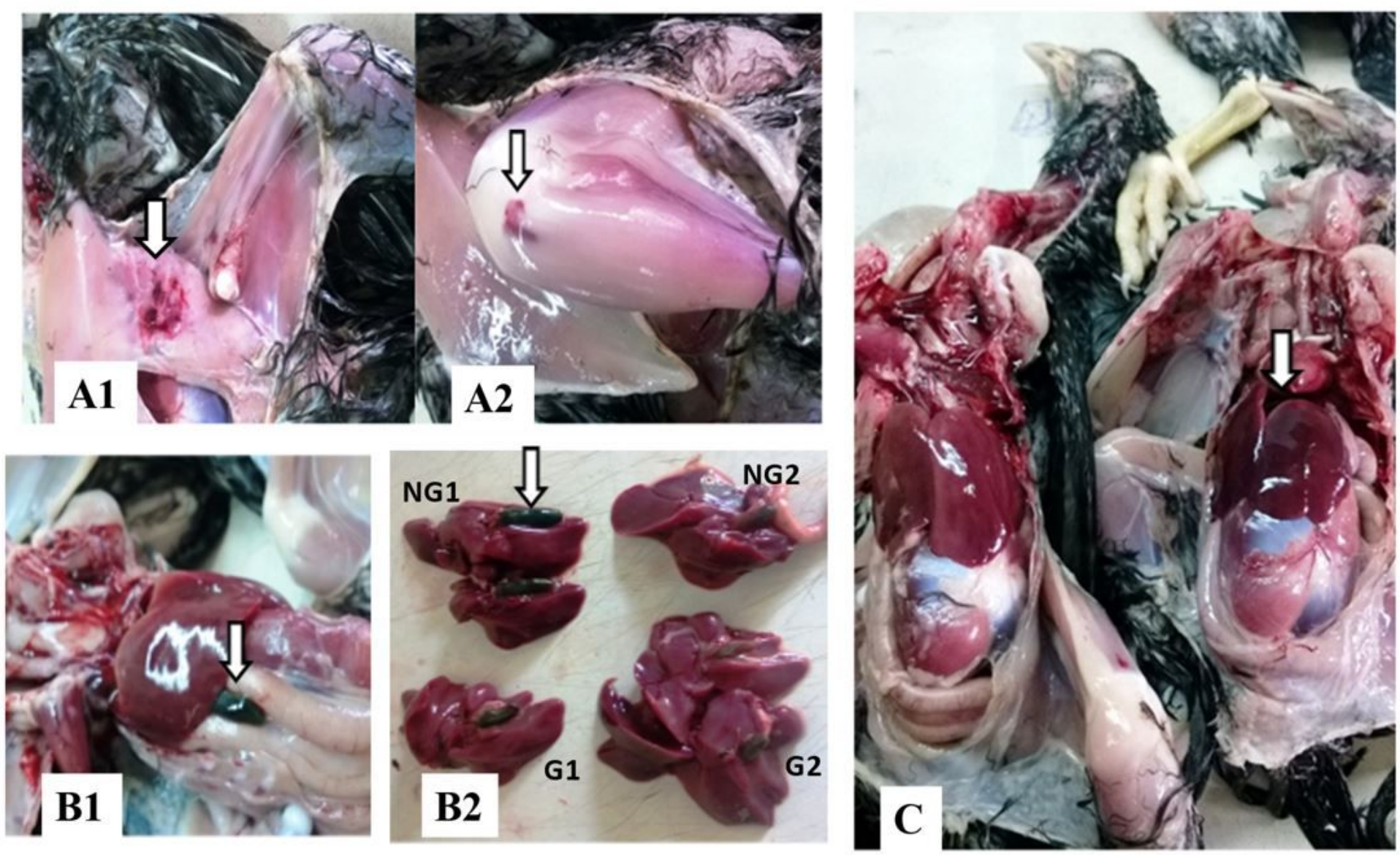

Figure 9

Gross pathological lesions observed in cockerels fed garlic-meal and administered acetaminophen. A: Ecchymotic haemorrhage (arrows) in the inguinal region (A1) and hock joint (A2) of 8 week-old cockerels at 5 days post-administration of acetaminophen (NG1). B1: Engorged gall bladder (arrow) extended beyond the liver margin in 8 week-old cockerel on garlic feed-inclusion and administered acetaminophen (G1). B2: Liver and gall bladder from 9 week-old cockerels. NG1 showing remarkably more engorged gall bladder (arrow) than $\mathrm{G} 1$ (both groups at 8 days post-administration of acetaminophen). C: Left carcassNG2. Right carcass-NG1, showing congested and swollen liver (arrow). 



\section{Figure 10}

Photomicrograph of liver (x400) of 8 week-old cockerels, 5 days post-administration of toxic dose of acetaminophen $(300 \mathrm{mg} / \mathrm{kg}$ body weight - NG1 and G1) showing vacuolar degeneration (a), coagulative necrosis (b), and mononuclear cells infiltration (c). 

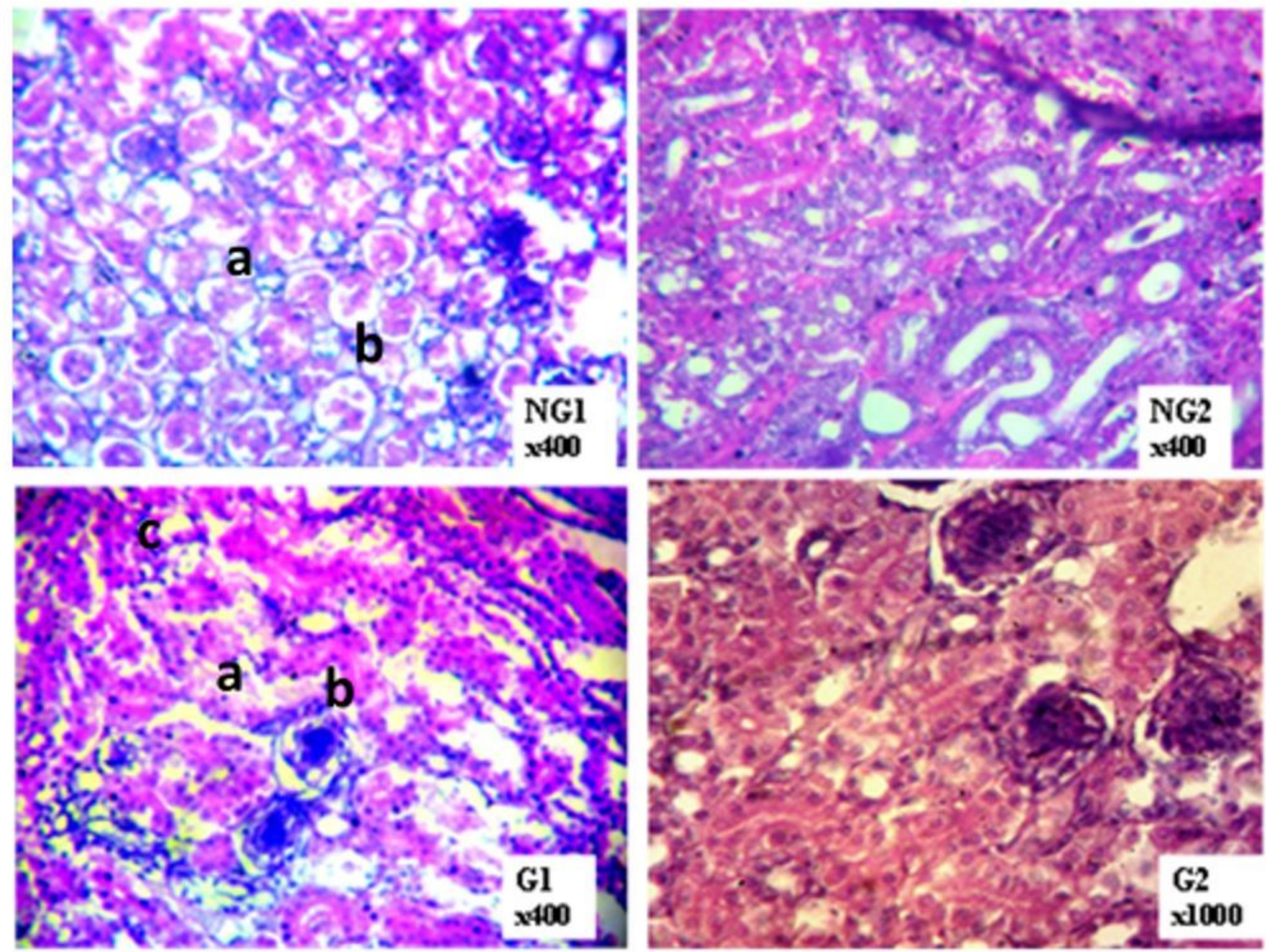

\section{Figure 11}

Photomicrograph of kidneys of 8 week-old cockerels, 5 days post-administration of toxic dose of acetaminophen $(300 \mathrm{mg} / \mathrm{kg}$ body weight - NG1 and G1) showing tubular epithelial necrosis (a), glomerullar degeneration (b) and mononuclear cells infiltration (c). 

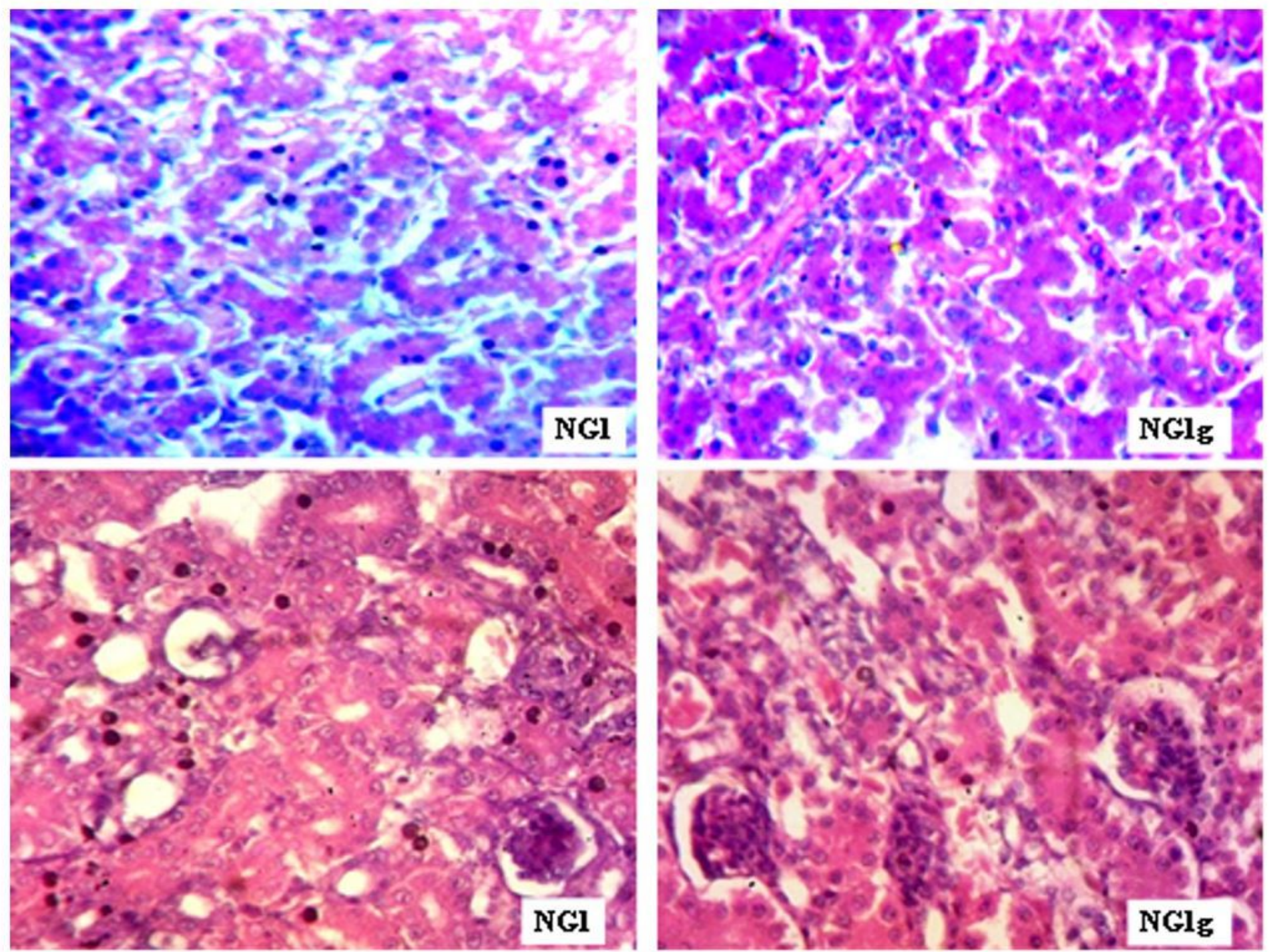

\section{Figure 12}

Photomicrograph of the liver (top) and kidney (bottom) of 10 week-old cockerels, 14 days postadministration of toxic dose of acetaminophen $(300 \mathrm{mg} / \mathrm{kg}$ body weight) and 6 days post-feeding with garlic-meal (NG1g), showing milder cellular necrosis and less mononuclear cells infiltration in NG1g (x400).

\section{Supplementary Files}

This is a list of supplementary files associated with this preprint. Click to download.

- GarlicHepatoNephrotoxicityData.xlsx 